\title{
The Role of Knowledge Management and Data Mining in Improving Educational Practices and the Learning Infrastructure
}

\author{
Areej Fatemah Meghji ${ }^{1 a}$, Naeem Ahmed Mahoto ${ }^{1 b}$, Mukhtiar Ali Unar², \\ Muhmmad Akram Shaikh ${ }^{3}$
}

RECEIVED ON 06.02.2019, ACCEPTED ON 03.05.2019

\begin{abstract}
Higher Educational Institutes hold a central and vital role in the knowledge economy. Knowledge generated by these institutes needs to be collected and disseminated to bring about improvement in not only student learning and performance, but also in educational practices, processes and the society in general. Sadly, in many institutes, this knowledge is rarely recognized, captured, analysed or utilized. Apart from the need for improved learning outcomes, rapid growth in educational data and technology has motivated several educational institutes to implement Knowledge Management (KM). KM is the key to enable educational institutes reach their goals and achieve their objectives.

This paper explores the basic concept of KM and addresses the need of KM in higher educational institutes by proposing a framework to improve knowledge processes and practices in academia. This paper also highlights the role of data mining in facilitating KM in higher education through a case study that focuses on aspects of student management. Using data mining methods of pattern discovery and association rule mining, interesting patterns have been discovered from academic data that can be used for effective pedagogical decision making. The applications and challenges faced in the implementation of KM within higher educational institutes have also been briefly discussed.
\end{abstract}

Keywords: Knowledge Management, Knowledge Sharing, Higher Education, Knowledge Discovery, Education

\section{INTRODUCTION}

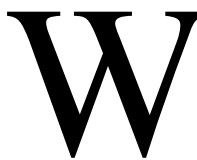

ith a fine line separating one from the other, data, information and knowledge

are related concepts [1]. Data are considered to be raw facts and figures, which are transformed into information when placed into context. Information depicts relationships and patterns, whereas knowledge is the understanding built by means of information [2].

Knowledge empowers individuals and organizations to survive in constantly shifting environments and can be categorized as a) explicit and b) tacit [3-4]. The former kind of knowledge resides in books and is

\footnotetext{
${ }^{1}$ Department of Software Engineering, Mehran University of Engineering and Technology, Jamshoro, Pakistan. Email: aareej.fatemah@faculty.muet.edu.pk (Corresponding Author), ${ }^{b}$ naeem.mahoto@ faculty.muet.edu.pk

${ }^{2}$ Department of Computer Systems Engineering, Mehran University of Engineering and Technology, Jamshoro, Pakistan.

Email: mukhtiar.unar@faculty.muet.edu.pk

${ }^{3}$ Pakistan Scientific and Technological Information Centre (PASTIC), Islamabad, Pakistan. Email: akramshaikh@hotmail.com
}

This is an open access article published by Mehran University of Engineering and Technology, Jamshoro under CC BY 4.0 International License. 
expressed using numbers, symbols, words, formulas, universal principles and so forth. This kind of knowledge can be transferred systematically. For example, methodologies, procedures, patents, services and products are explicit knowledge of an organization. Tacit knowledge is profoundly entrenched in individuals' personal experiences, practices and actions, making it hard to formalize and share with others. Examples of tacit knowledge include skills, individuals' beliefs, values and ideas [5].

As important as it is to collect knowledge, this effort becomes useless if the acquired knowledge is not put into action [6]. Karl Wiig, famous author and cofounder of the International Knowledge Management Network, used the term 'manage knowledge' during an international conference in 1986 [7]. Knowledge Management (KM), that became an established discipline in 1991 [8], can be defined as a continuous process in which an organization constructs, stores, organizes, shares and analyses its knowledge in ways that directly impact performance [9]. This approach gains knowledge from the environment and then improves it through innovative methods allowing organizations to ascertain the most important facets of knowledge and then use that knowledge to make better decisions [10]. An imperative activity within an organization, KM allows the acquisition, sharing and use of knowledge to attain organizational goals [11]. An essential goal of KM is ensuring the availability of knowledge - at the right time, within right formats and budget - to the right entities, so that specific decisions can be taken at specific times [12]. KM has been well established in business [13], and now, globalization has opened doors for evolutionary activities and KM practices to enter academia [14].
Higher Education Institutes (HEI) hold a central role in the knowledge economy; they are responsible for the production of top quality knowledge assets, in the form of high class graduates, who in turn play a direct role in not only social growth and economic development, but also in an increase of the knowledge pool. Two major forms of knowledge can be extracted from HEI, namely organizational/operational and academic knowledge [15]. The mechanics of running the institute, business policies, practices, strategies as well as the strength and weakness of the institute, result in organizational knowledge. Academic knowledge results from day to day activities of learning and teaching. In most HEI, departmental silos add to the difficulty of collecting and managing academic knowledge; directly hindering the process of identifying critical knowledge assets of the institute. As a result, these institutes manage organizational knowledge while they continue to suffer with the management of academic knowledge. Instead of being the front runners, HEI have been slow in adopting KM practices and making explicit efforts to not only handle, but also improve processes directly involved in the creation of knowledge. KM offers these institutes the opportunity to become proactive in their decision making approach by addressing their greatest challenge - effectiveness [16].

This paper examines the concept of KM in general and specifically the relevance and need of KM within HEI. In particular, the focus of this paper is on enhancing KM processes within academia by applying wellestablished knowledge engineering techniques. A framework has been proposed to enhance educational processes for KM followed by a case study that helps grasp the benefits that can be attained from KM in education. This paper concludes after a discussion on 
the usability in terms of application domain, limitations and challenges KM faces in education.

\section{KNOWLEDGE MANAGEMENT IN EDUCATION}

Although knowledge is a strategic resource which is essential for the prosperity of HEI [17], the creation of knowledge is one of the greatest challenges faced by these institutes [18]. Despite generating tremendous amounts of data, in various forms, through varied sources, these institutes lack mechanisms that can convert this data to knowledge.

Drucker [19] asserts that for institutes existing in this day and age, an important challenge is building efficient practices for management of knowledge. KM can aid HEI accumulate and analyse data, transform it to knowledge, and apply intelligence through which these institutes can meet their objectives. The interest for introducing $\mathrm{KM}$ practices in education has been expressed in [20-22].

Over the years, significant steps have been taken to better collect, store, manage, utilize and share academic and organizational knowledge in HEI [23]. Development of a KM framework guides institutes before actual implementation to guarantee their KM endeavours reach fruition. It also permits learners to comprehend the fundamentals of knowledge itself and makes ease for additional learning.

The framework by Martin and Marion [24] includes processes of production, integration and use to identify specific leader roles and their impact on how knowledge is processed. The framework by Sedziuvienne and Vveinhardt [15] includes four processes: identification, creation, storage and sharing of knowledge. Pinto [25] introduced a KM framework based on three layers comprising of technological infrastructure, knowledge systems and KM practices. These layers support and promote the process of knowledge creation, storage, sharing and application. Alavi and Leidner [26] view institutes as knowledge systems. Using the cognitive and social nature of institute knowledge they lay a generalized conceptual foundation of how knowledge can be created, stored/retrieved, transferred and applied within an institute. The conceptual framework by Zaki and Zubairi [27] aims to improve the quality assurance system within education institutes. Based on a collected survey, their findings strongly suggest the implementation of KM will result in an increase in the quality of education. However, the practical extraction and implementation of knowledge have not been addressed. Judrups [28] presents an integration of KM and EL (e-learning) portraying KM phases with elearning advancements. This model is enhanced with e-learning technologies and supports e-learning adoption in KM. However, practical implementation, methodological support and expert involvement need to be addressed.

\section{PROPOSED FRAMEWORK OF KNOWLEDGE MANAGEMENT}

The proposed framework comprises of 5 knowledge processes: collection, organization, discovery, storage and sharing (see figure.1). Unlike the existing frameworks, a team of experts tasked to closely work with educators to enhance education and learning at the institute level, gradually reduce departmental/organizational silos and ensure educators are not burdened with KM tasks has also been proposed. Also, organization is treated as a separate process indicating its significance in the KM Cycle (KMC).

Collection: The first step in designing a $\mathrm{KM}$ framework is the identification of data sources that can guide and shape policies and pedagogy. Some potential sources of data have been highlighted in Figure.2. The current system of education does not inherently extract knowledge from academic data, nor does it have mechanisms in place to collect and analyse this data for improved learning. Despite this, some educators have taken it upon themselves to collect academic data from institutional records, in the 


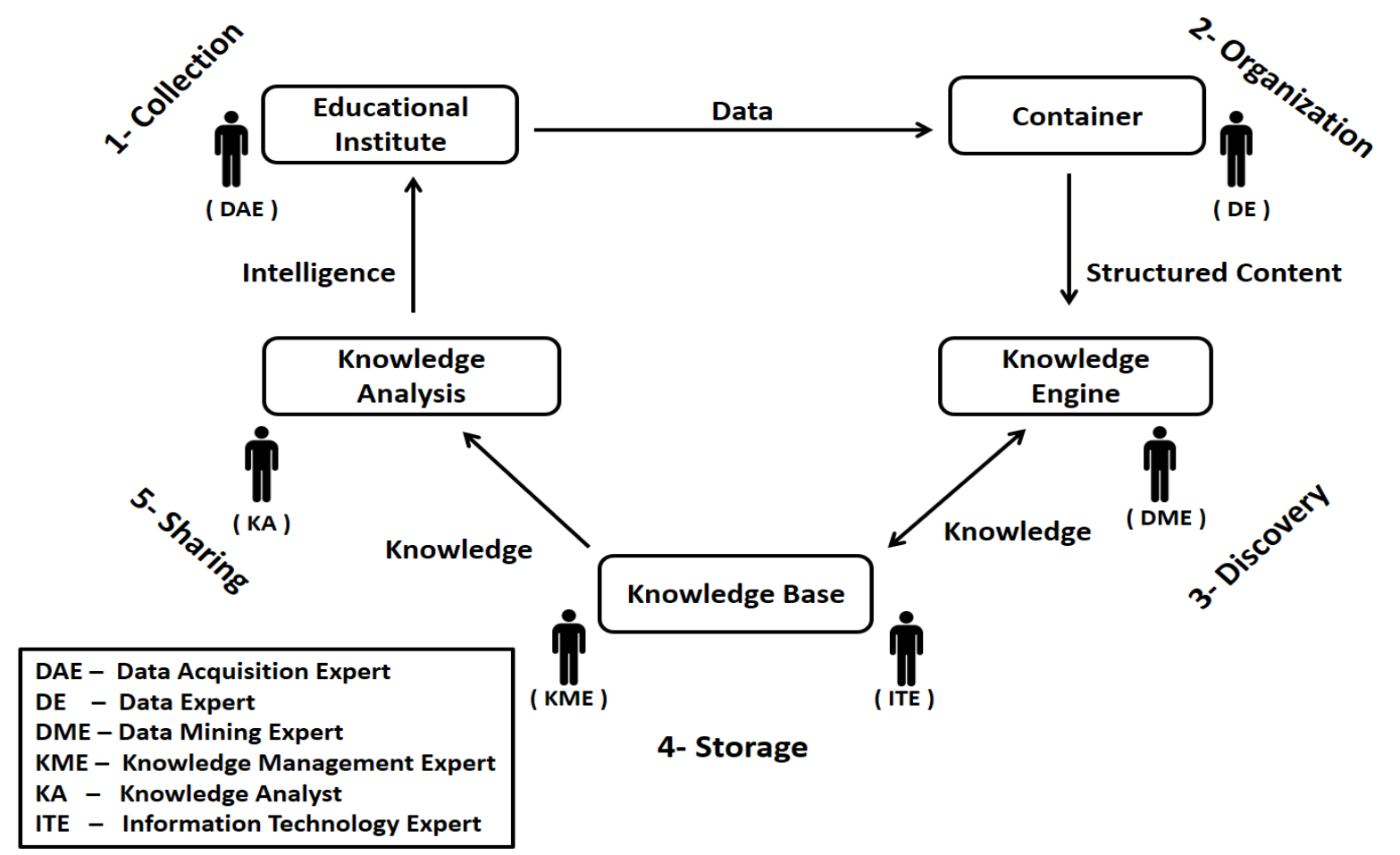

Fig. 1: A Framework for Knowledge Management in Education

form of student bio-data, geo demographics and assessment marks, which are stored by all HEI. They have also collected behavioural data through surveys, observations and feedback. This effort, although monumental and worth appreciation, has focused on academic improvement in a specific course/subject or in a specific department. This subjective analysis and lack of uniformity in the data collection, storage and knowledge extraction mechanism can be tackled by having dedicated experts work closely with the educators to bring about an overall improvement in academic success at the institute level.

Apart from the traditional sources of learning data, recent years have seen an increased use of web and metric based learning systems in education [29]. Academic data can also be obtained from student logs, gaming systems and social media. It is vital to obtain feedback from faculty and administrative staff for the management of organizational knowledge. An effective KM framework needs data from both internal and external sources [30]. Thus, it is important to collect data from the industry, employing organizations and alumni as this can help structure curricula and competency development. Once these sources are identified, a framework of Information and Communication Technologies (ICT) facilitates the acquisition of data from these sources.

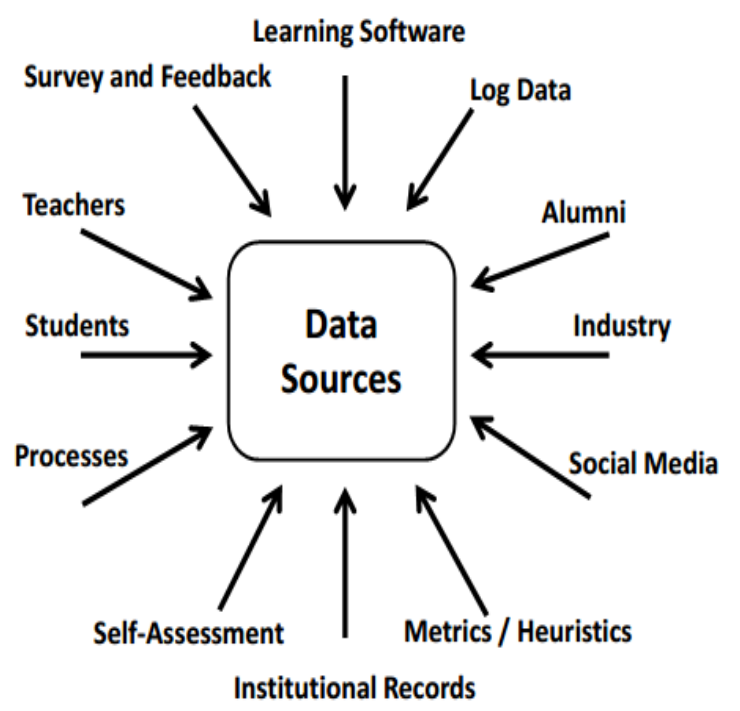

Fig. 2: POTENTIAL SOURCES OF DATA

Organization: Once the data is collected, it needs to be converted to knowledge. Since the data arises from Mehran University Research Journal of Engineering and Technology, Vol. 39, No. 2, April 2020 [p-ISSN: 0254-7821, e-ISSN: 2413-7219] 
various sources and exists in several formats, it may contain duplicate or missing data which may cause incorrect or even misleading statistics. High quality data ultimately leads to high quality mining results. Expert involvement is thus crucial to ensure this data undergoes rigorous scrutiny before it is used for the extraction of knowledge and intelligence.

Organization of data is thus an immensely important step which includes, but is not limited to: data cleaning that sifts through data to tackle missing values, errors, outliers or discrepancies that cause a reduction in quality, integration that combines data emerging from various sources and formats (learning software, educational records, survey data etc.) into a collective student repository, transformation that, dependant on the Data Mining (DM) method chosen for analysis, normalizes, binarizes, discretizes and/or aggregates data, and reduction that selects aspects of data that contribute the most to the analysis at-hand as working with irrelevant data can decrease the accuracy of many algorithms. These steps can be carried out in any order. Depending on the methodology followed, steps may even be missed or revisited [31].

Discovery: As the saying, attributed to both W.E. Deming and Peter Drucker goes, you can't manage what you don't measure [32]. Due to the vast amount of data available today, HEI can measure, and hence know, more about their students' learning behaviour, faculty satisfaction and administrative effectiveness. However, the lack of a central mechanism, that can convert this data to knowledge, and dedicated experts, that can disseminate this knowledge for improved decision making, is restricting HEI from reaching their full potential.

The knowledge engine ensures the extraction of knowledge by applying vigorous routines of DM on the structured information. DM has the unique capability of turning vast amounts of data into knowledge [33]. It is a process that discovers patterns in data sets using methods at the intersection of databases, statistical analysis, machine learning and artificial intelligence. After knowledge extraction, DM transforms knowledge into a structure that is understandable and can be further used. The actual DM task revolves around the exploration of data with the intent of discovering new, as yet unknown, and potentially interesting patterns [34].

Storage: It has been observed through empirical studies that just as an institute discovers knowledge, it also tends to forget (lose track of) the discovered knowledge [35]. Storage of knowledge in a knowledge base is an essential step that allows institutes to review and learn from previous discoveries. This way the best practices of tried and tested schemes can be implemented and, at the same time, pitfalls avoided.

Sharing: The final step is dissemination of knowledge to the concerned department and management of the HEI. The application of knowledge results in emergence of new data beginning the cycle anew.

\subsection{Roles in Knowledge Management}

Change within the sector of education will not take place simply by bringing teachers in contact with technology [36]. A lack of familiarity in using technology and advanced tools can act as inhibitors to the knowledge discovery process. Specific roles need to be defined for carrying out KM activities within educational institutes. The following team of six experts, that together make the knowledge cell of the institute, is proposed to ensure efficient processing of knowledge at each stage of the KMC.

- A Data Acquisition Expert (DAE) is proposed to acquire data from the potential sources (highlighted in fig.2). The DAE should also conduct surveys to obtain feedback where direct sources of data are not available.

- A Data Expert, an expert at handling various formats of data and working with advanced databases, is proposed to tackle the task of structuring, cleaning and transforming data into a form that will yield maximum knowledge, in the form of patterns, features, rules etc., in the next stage.

- A Data Mining Expert is proposed to proficiently run DM methods on data from the previous stage. Running various DM methods, this expert will discover knowledge that will help in pedagogical decision making. 
- Once knowledge is discovered it needs to not only be stored, but also organized in a manner that allows quick access and retrieval. A Knowledge Management Expert is proposed to structure the discovered knowledge.

- A Knowledge Analyst is poposed to analyse the discovered knowledge and closely work with the administration of the HEI and a representative of each department of the institute to use this knowledge for shaping educational practices, academic courses and business policies.

- An Information Technology Expert (ITE), an essential member of the framework, is proposed to cover each of the knowledge processes to ensure a proper IT infrastructure is in place for each expert to communicate with each other and with the institute.

\section{KNOWLEDGE DISCOVERY FROM ACADEMIC DATA - A CASE STUDY}

The case study presented in this section demonstrates how the proposed KM framework can be utilized for decision making and improvement of student performance, in terms of final exam outcome, using academic knowledge generated from student behavioural data.

\subsection{Collection}

The collected data belongs to undergraduate students of the department of Software Engineering, Mehran University of Engineering and Technology, Jamshoro, Pakistan. 176 students, in the 3rd year of Bachelor of Engineering (B.E) in Software, were observed for one semester. Their behaviour in terms of class performance, attention, seating position, class interaction etc. were observed and collected. A sample of the collected data has been presented in Table 1 .

The collected data comprised of 13 attributes. This case study focuses on a relation between these attributes. A description of the attributes is provided in Table 2 .

\subsection{Organization}

Initially data of 176 students was collected. Records containing missing values were disregarded. Thus, a total of 174 records have been used in the next stages. Fields indicating test scores were normalized into possible values of excellent, good, average, belowaverage and poor. In order to delve deeper into an understanding of student performance and to help pedagogical decisions, student data has been segmented into 2 parts. Data of students having A+ and A grades, and those having B, C, D or F grades were separated into two datasets. This stage thus resulted in three datasets - a complete dataset comprising of all student records, a reference dataset comprising of students that have excelled in the class (dataset-1) and a dataset that comprised of the remaining students (dataset-2).

\subsection{Discovery}

This case study explores knowledge discovery through Pattern Mining [37] and Association Rule Mining (ARM) [38]. The goal of pattern mining is to find frequent patterns within a dataset. Given a dataset, patterns are sets of items that frequently occur together, thus making these items strongly correlated.

ARM, a well-known DM technique, is used to discover relations among attributes in a given database by generating if-then statements concerning attribute values [39]. Association rules aim at discovering cooccurrences between itemsets. ARM comprises of two steps: 1) Discovering all frequent item sets in a given dataset satisfying a specified minimum support threshold, and 2) generation of association rules at a given minimum confidence threshold.

Consider the example of five students presented in Table 3. Each student possesses different attributes, and these attributes can be possessed in varying degrees. Student-1 may show average attention in class whereas student- 2 may show good attention. The same can be true for note-taking and any other number of attributes. The task of pattern mining is to ascertain a support value (frequency of the attribute within the dataset) for each attribute and combination of attributes. Pattern mining can thus be used to draw conclusions on which attribute is exhibited the most by students' as well as the varying degrees of combination of attributes exhibited together. Similarly, ARM can be used to draw associations between different student attributes.

Mehran University Research Journal of Engineering and Technology, Vol. 39, No. 2, April 2020 [p-ISSN: 0254-7821, e-ISSN: 2413-7219] 
Table 1 A sample of collected student data

\begin{tabular}{|l|l|l|l|l|l|l|l|}
\hline Sno & Performance & Attention & $\begin{array}{l}\text { Seating } \\
\text { Position }\end{array}$ & $\begin{array}{l}\text { Note } \\
\text { Taking }\end{array}$ &.. & Excuses & Grade \\
\hline 001 & Good & Good & Front & Good &.. & Rare & A+ \\
\hline 002 & Average & Average & Middle & Good &.. & Average & B \\
\hline$\cdot$ & $\cdot$ & $\cdot$ & $\cdot$ & $\cdot$ &.. & $\cdot$ & $\cdot$ \\
\hline$\cdot$ & $\cdot$ & $\cdot$ & $\cdot$ & $\cdot$ &.. & $\cdot$ & $\cdot$ \\
\hline 175 & Good & Excellent & Front & Good &.. & Never & A \\
\hline 176 & Excellent & Good & Middle & Excellent &.. & Never & B \\
\hline
\end{tabular}

Table 2 Student attributes and their possible values

\begin{tabular}{|c|c|c|c|}
\hline Sno & Attribute & Description & Possible Value \\
\hline 1 & class_perf & Student class performance & \multirow{7}{*}{$\begin{array}{l}\text { Excellent } \\
\text { Good } \\
\text { Average } \\
\text { Below Average } \\
\text { Poor }\end{array}$} \\
\hline 2 & class_att & Attention given to lectures & \\
\hline 3 & inter_class & Student-Teacher in-class interaction & \\
\hline 4 & inter_aftrclass & Student-Teacher after-class interaction & \\
\hline 5 & note_taking & Note-taking and maintenance & \\
\hline 6 & assg_sub & Student assignment submission record & \\
\hline 7 & test_marks & Student test scores & \\
\hline 8 & excuses_leave & Excuses made to leave class & \multirow{3}{*}{$\begin{array}{l}\text { Always } \\
\text { Mostly } \\
\text { Average } \\
\text { Rarely } \\
\text { Never }\end{array}$} \\
\hline 9 & assg_self & $\begin{array}{l}\text { Does the student make his/her own } \\
\text { assignemnt }\end{array}$ & \\
\hline 10 & class_project & Participation in class projects & \\
\hline 11 & seating_post & Student seating position & Front, Middle, Back \\
\hline 12 & f_grade & Final grade obtained & $\begin{array}{l}\mathrm{A}+, \mathrm{A}, \mathrm{B}+, \mathrm{B}, \mathrm{C}+, \mathrm{C}, \mathrm{D} \\
\mathrm{F}\end{array}$ \\
\hline 13 & f_outcome & Did the student pass or fail the course & Pass, Fail \\
\hline
\end{tabular}


Table 3 Pattern Mining in Education

\begin{tabular}{|c|c|c|}
\hline $\begin{array}{l}\text { Student } \\
\text { No. }\end{array}$ & Attributes Possessed & Attribute Support \\
\hline 1 & $\begin{array}{l}\text { Attention: Avg, } \\
\text { Note-Taking: Good }\end{array}$ & $\begin{array}{l}\text { Attention: } \text { Avg }=60 \% \\
\text { Attention: } \text { Good }=40 \%\end{array}$ \\
\hline 2 & $\begin{array}{l}\text { Attention: Good, } \\
\text { Note-Taking: Avg }\end{array}$ & $\begin{array}{l}\text { Note-Taking: } \text { Avg }=40 \% \\
\text { Note-Taking: Good }=60 \%\end{array}$ \\
\hline 3 & $\begin{array}{l}\text { Attention: Avg, } \\
\text { Note-Taking: Good }\end{array}$ & $\begin{array}{l}\text { Attention: Good and Note-Taking: Good }=20 \% \\
\text { Attention: Good and Note-Taking: Avg }=20 \%\end{array}$ \\
\hline 4 & $\begin{array}{l}\text { Attention: Avg, } \\
\text { Note-Taking: Avg }\end{array}$ & $\begin{array}{l}\text { Attention: Avg and Note-Taking: Good }=40 \% \\
\text { Attention: Avg and Note-Taking: Avg }=20 \%\end{array}$ \\
\hline 5 & $\begin{array}{l}\text { Attention: Good, } \\
\text { Note-Taking: Good }\end{array}$ & \\
\hline
\end{tabular}

\subsubsection{Knowledge Discovery through Pattern Mining}

Considering the attributes presented in Table 2, pattern mining has been used on student data to show various patterns exhibited by the students in a class. Some interesting patterns observed in the complete dataset have been presented in Figure 3.

Apparent from Fig.3, a little over 70\% of students have cleared their final exams. Almost 50\% students never interacted with the teacher after class and $46 \%$ never took part in project work. $30 \%$ students that never made assignments on their own sat in the back of the class and $15 \%$ that sat in the front of the class exhibitted good class performance.

Fig. 3 provides a general understanding of patterns exhibited by students in a class. Now what if the management wishes to see how these individual attributes affect the final outcome of the students. Does good class performance influence whether the student will pass or fail? Does submitting assignments influence the final grade of the student?

To gain a better understanding of how each attribute considered in this study influences the final outcome, pattern mining was used to monitor patterns exhibited by bright students of a class (dataset-1) and compare these patterns with the remainder of the class (dataset2). Each attribute along with its support value has been presented in Figure 4 and Figure 5.

Fig. 4 shows support values for attributes possessed by the bright students (dataset-1). It was observed that out of all students that secured an A+ or an A grade in their studies, $50 \%$ students exhibited excellent class performance during the session whereas nearly $45 \%$ students exhibited good class performance. $70 \%$ students showed excellent attention during lectures, almost $90 \%$ students never made an excuse to leave class, almost $60 \%$ students performed excellent during class tests, submitted their assignments regularly, had excellent interaction during lectures, took part in class projects and sat in the front or middle of the class. An interesting pattern was seen in terms of interaction after class. Almost the same percentage of students that had excellent, good, average and absolutely no interaction with the teacher after class have all secured an A+ grade, clearly reflecting that this parameter does not influence the final grade. 
The Role of Knowledge Management and Data Mining in Improving Educational Practices and the Learning Infrastructur

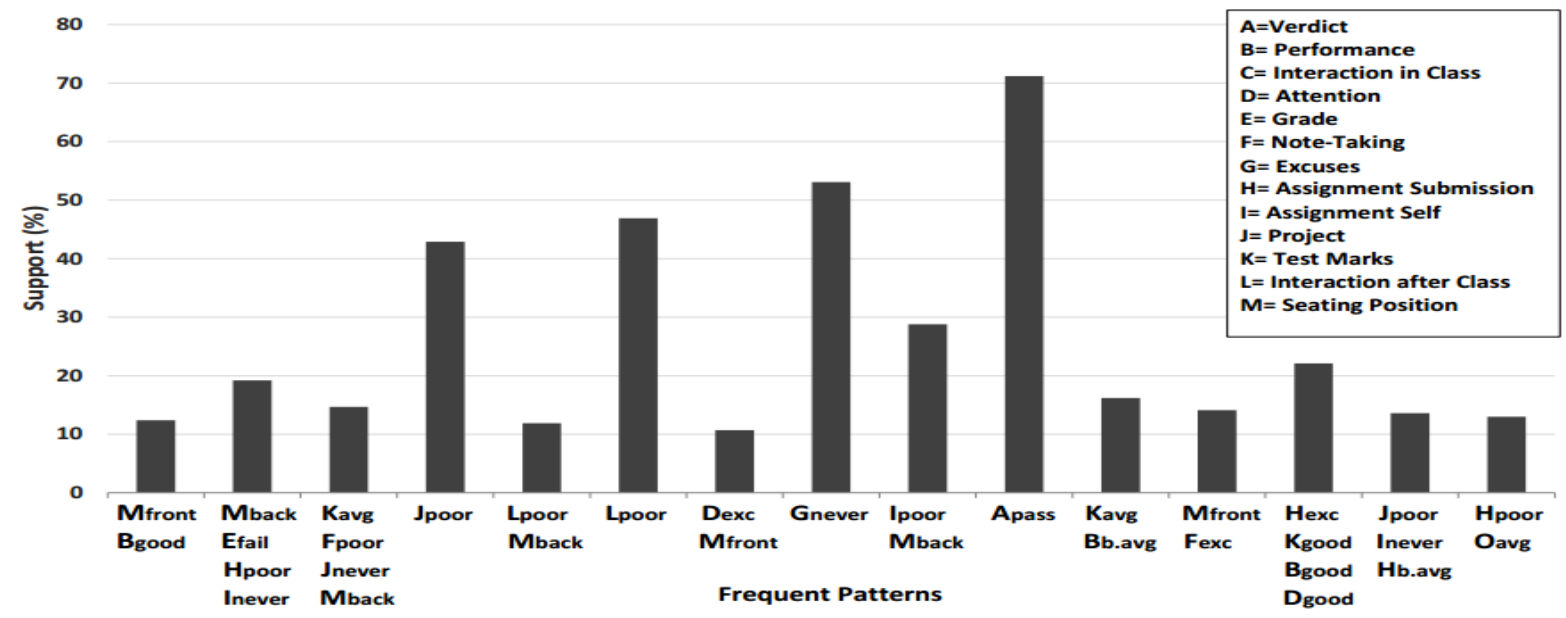

FIG. 3: PATTERNS IN THE COMPLETE DATASET

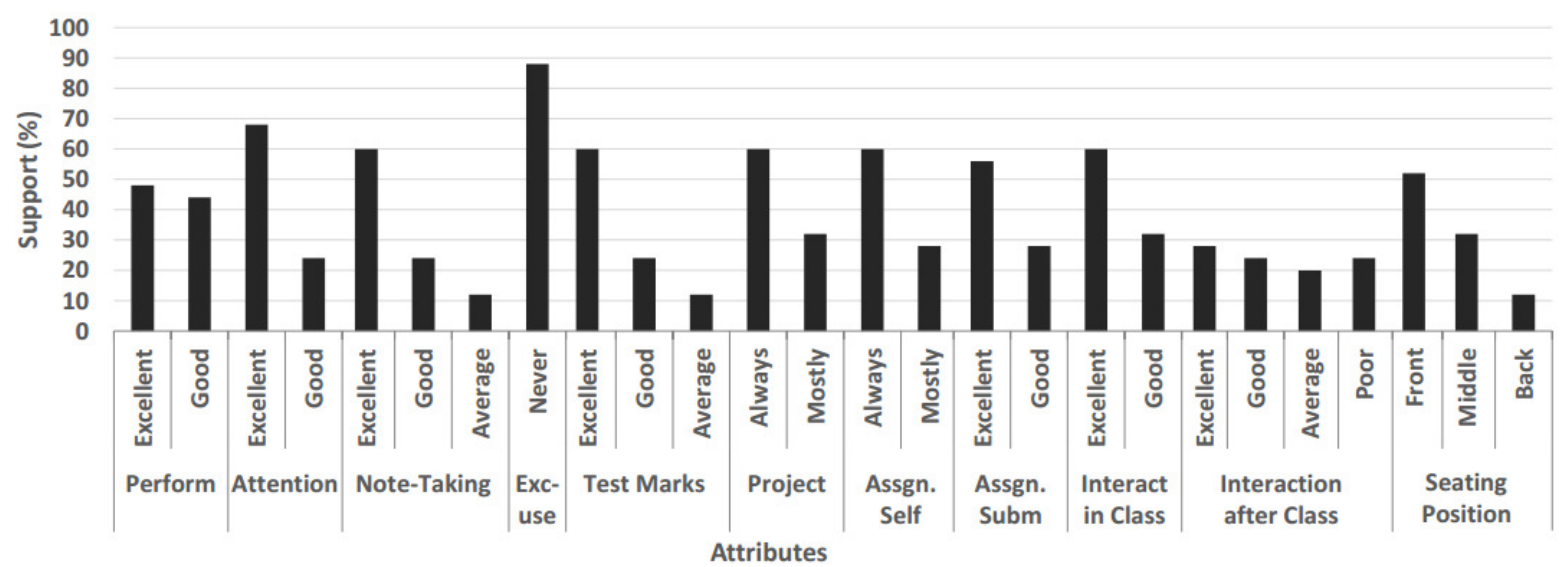

FIG 4: PATTERNS OF DATA SET 1

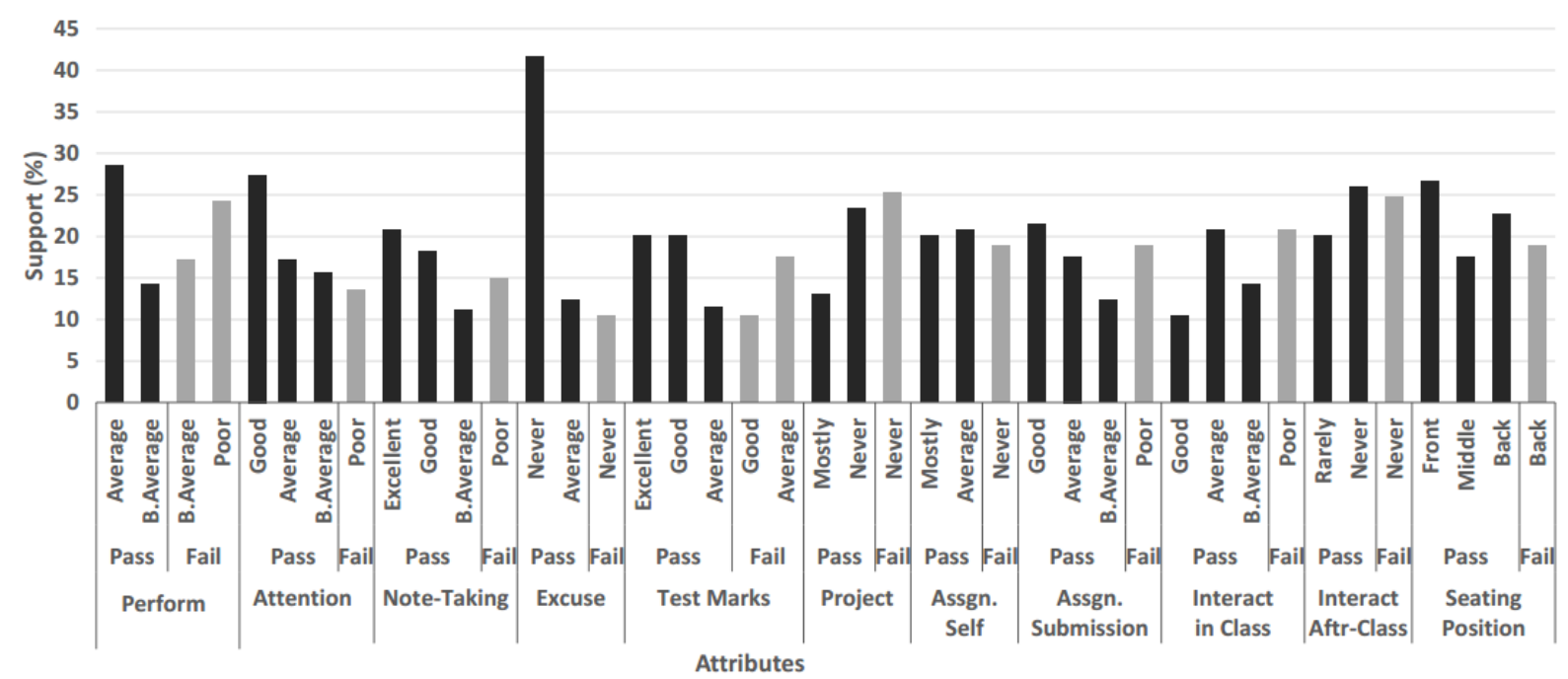

FIG.5: PATTERNS OF DATASET-2 (PASS-FAIL)

Mehran University Research Journal of Engineering and Technology, Vol. 39, No. 2, April 2020 [p-ISSN: 0254-7821, e-ISSN: 2413-7219] 
The other data set for this study comprises of two sets

of students: 1) students that cleared their exams (Grade

B, C, D) and 2) students that failed their exams (Grade

F). To help pedagogical decision making practices, patterns of each attribute have further been subdivided in terms of patterns for an attribute shown by students that have passed their exams and patterns of an attribute shown by students that have failed their exams (see Fig. 5).

Examining Fig. 4 and Fig. 5, a clear difference can be seen in attributes values. Considering the attribute performance, $30 \%$ students that exhibited an average class performance have cleared their final exams. Whereas almost $18 \%$ students that exhibited below average and $25 \%$ that exhibited poor class performance during the session have failed their final exams. Similarly, students paying varying degrees of attention to lectures (good, average or even below average) have cleared their final exam, whereas poor attention has resulted in failure. Similar to the bright students, the pattern 'interaction after class' does not seem to affect the final outcome; students that have poor interaction after class have gone on to clear as well as fail their exams. Another interesting factor is the marks obtained in 'class tests'. Students that have cleared their papers had excellent, good and average scores in class tests. Students that have failed also had good and average marks in class tests. Thus a good score in class tests cannot serve as an indicator for final assessment.

From these observations it is evident that students that do not pay sufficient attention to lectures, exhibit below average class performance and never make their own assignments are going to suffer at the end of the term.

\subsubsection{Knowledge Discovery through Association Rule Mining}

Association rule support, confidence and lift have been taken as evaluation matrices for association rules in the study under discussion. Some interesting rules that can be used to manage student final grades are listed below.

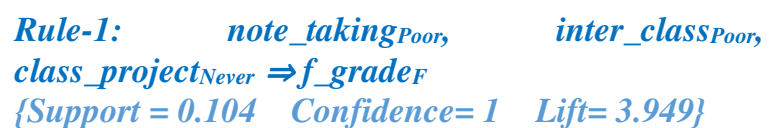

Rule-2: $\quad$ assgn_self Rare, $_{2} \quad$ class_perf Poor $_{\text {, }}$ note_taking ${ }_{\text {Poor }}$, class_attoor $\Rightarrow f \_$grade $F$

$\{$ Support $=0.104$ Confidence $=1 \quad$ Lift $=5.923\}$

Rule-3: class_perfPoor, assgn_selfRare, class_attpoor, assgn_subPoor, note_taking ${ }_{\text {Poor }} \Rightarrow f \_$grade $F$

$\{$ Support $=0.123$ Confidence $=1 \quad$ Lift $=3.020\}$

Rule-4: $\quad$ class_project Never, $_{\text {seating_post }}$ Back, inter_classPoor $\Rightarrow f \_$grade $F$

$\{$ Support $=0.110$ Confidence $=1 \quad$ Lift $=3.020\}$

Rule-5: excuses_leavepoor, class_attExcellent, assgn_self ${ }_{\text {Mostly }} \Rightarrow f \_$grade $_{A+}$

$\{$ Support $=0.160$ Confidence $=1 \quad$ Lift $=1.190\}$

Rule-6: class_perf Good, note_taking ${ }_{G o o d}, c l a s s \_a t t_{G o o d}$ $\Rightarrow f_{\_}$grade $_{A+}$

$\{$ Support $=0.12 \quad$ Confidence $=1 \quad$ Lift $=1.316\}$

Interpretation: It is evident from the association rules that attributes of note taking, attention, self- solving of assignments and class performance greatly influences student final grades. For instance, poor note-taking, attention and a tendency to rarely self-solve assignments results in an F-grade, whereas good notetaking, attention and class performance results in an A+ grade. Also, a preference of seating in the front or middle of the classroom results in better grades as opposed to seating in the back of the class. In addition to these factors, students that participate in class projects and have good class interaction tend to do better in exams compared to students that refrain from such activities.

\subsection{Storage}

The discovered knowledge is stored in the institute's knowledge base and organized under student behaviour. 


\subsection{Sharing}

Educational institutes can use this knowledge to gain insights into behaviour that stimulates success and take preventive measures to avoid an increase in patterns that lead to failure. Students exhibiting patterns that lead to poor grades can be gently counselled. Interventions can be planned early on. Mechanisms can be devised to engage students in class activities and encouragement can be given to foster behaviour that will ultimately lead to better performance.

\section{APPLICATIONS, LIMITATIONS AND CHALLENGES OF KM IN EDUCATION}

KM can support every aspect of an educational institute's mission. It has the potential to benefit strategic planning, administrative services, teaching methodology, student management as well as curriculum structure [40]. A limitation of the proposed framework and its implementation in HEI arises from the extensive use of technology. The framework is as good as the data and DM methods used to explore and learn from this data. Advanced methods of prediction, classification, clustering, etc., have the potential of unveiling a gold mine of knowledge and intelligence and can be used to discover interesting facets of knowledge [41]. In order to truly integrate KM practices in the field of education, the collective accumulation and analysis of knowledge from multiple HEI is proposed in a knowledge base maintained by the Higher Education Commission of the country.

As the world of education moves into an increasingly digital world, every device used for the process of learning provides more and more data to process. Also, the creation and sharing of knowledge occurs not just within educational institutes, but also on social media, discussion blogs and online channels [42]. A challenge for KM systems is the capture and use of relevant data and its conversion into educational knowledge.

Despite all these challenges, the biggest challenge for $\mathrm{KM}$ to flourish is the reluctance of HEI to recognize knowledge as intellectual capital and the creation of a knowledge environment. It is important to keep in mind that technology is not a solution in itself [25]. It needs to be supported by all the components of the KM framework, including an efficient KM strategy and dedicated experts that ensure HEI extract knowledge and utilize it to foster an environment of better learning.

\section{CONCLUSION AND FUTURE WORK}

Undertaking $\mathrm{KM}$ at the institute level, although daunting, is a necessary task. This paper addresses the need of $\mathrm{KM}$ in the field of education. A framework has been proposed with the aim of improving knowledge processes and practices within higher education. Using advanced DM techniques, the proposed framework is equipped to support every aspect of a higher educational institute's mission. It has the potential to benefit administrative services, teaching methodology, curriculum structure and student management. To ensure the efficient processing of knowledge and use of technology, a team of experts has been proposed with the framework. The case study presented in this paper demonstrates the practical implementation of the proposed framework in the context of student management. Using DM methods of pattern discovery and association rule mining, interesting patterns have been discovered from academic data that can be used by educators to discover the potential of their students, provide timely interventions, make better pedagogical decisions and improve student learning. These results are a mere glimpse of the endless potential of KM in education. Increasing the data to the KM engine will allow the true power of KM to become evident. Future work will focus on the implementation of the fore discussed measures in order to ensure the flow and improvement of knowledge along with the evaluation of the proposed framework.

\section{ACKNOWLEDGMENT}

This work has been performed under Institute of Information and Communication Technologies, Mehran University of Engineering and Technology, Jamshoro, Pakistan and funded by ICT endowment fund for sustainable development.

Mehran University Research Journal of Engineering and Technology, Vol. 39, No. 2, April 2020 [p-ISSN: 0254-7821, e-ISSN: 2413-7219] 


\section{REFERENCES}

[1] Shongwe, M.M., "An analysis of knowledge management lifecycle frameworks: Towards a unified framework", The Electronic Journal of Knowledge Management, Vol. 14, No.3, pp. 140-153, 2016.

[2] Zins, C., "Conceptual approaches for defining data, information, and knowledge", Journal of the American Society for Information Science and Technology, Vol. 58, No. 4, pp. 479-493, 2007.

[3] Chuang, C.H., Jackson, S.E., and Jiang, Y., "Can knowledge-intensive teamwork be managed? Examining the roles of HRM systems, leadership, and tacit knowledge", Journal of Management, Vol. 42, No. 2, pp. 524-554, 2016.

[4] Kogut, B., and Zander, U., "Knowledge of the firm, combinative capabilities, and the replication of technology", Organization Science, Vol. 3, No. 3, pp. 383-397, 1992.

[5] Laal, M., "Knowledge management in higher education", Procedia Computer Science, Vol. 3, pp. 544-549, 2011.

[6] Mobilla, M.D.C.M., "Experiences of Educational Inclusion in Colombia: Towards Useful Knowledge", RUSC, Universities and Knowledge Society Journal, Vol. 8, No. 1, pp. 55-65, 2011.

[7] Kuznetsova, E., "Exploring the Links between Knowledge Management and Leadership in Education", International Conference on Intellectual Capital and Knowledge Management and Organisational Learning, Academic Conferences International Limited, p. 167, 2016.

[8] Nonaka, I., and Von Krogh, G., "PerspectiveTacit knowledge and knowledge conversion: Controversy and advancement in organizational knowledge creation theory", Organization Science, Vol. 20, No. 3, pp. 635-652, 2009.

[9] Liao, S.H., "Knowledge management technologies and applications-literature review from 1995 to 2002", Expert Systems with Applications, Vol. 25, No. 2, pp. 155164, 2003.
[10] Newman, B., “An open discussion of knowledge management", The Knowledge Management Forum Archives, 1991.

[11] Hislop, D., Bosua, R., and Helms, R., "Knowledge management in organizations: A critical introduction", Oxford University Press, 2018.

[12] Holsapple, C.W., and Joshi, K.D., "Knowledge management: A threefold framework", The Information Society, Vol. 18, No. 1, pp. 47-64, 2002.

[13] Devi Ramachandran, S., Choy Chong, S., and Ismail, H., "The practice of knowledge management processes: A comparative study of public and private higher education institutions in Malaysia", Vine, Vol. 39, No. 3, pp. 203-222, 2009.

[14] Begoña Lloria, M., "A review of the main approaches to knowledge management", Knowledge Management Research \& Practice, Vol. 6, No. 1, pp. 77-89, 2008.

[15] Sedziuviene, N., and Vveinhardt, J., "The paradigm of knowledge management in higher educational institutions", Engineering Economics, Vol. 65, No. 5, 2009.

[16] Townley, C.T., "Will the academy learn to manage knowledge", Educause Quarterly, Vol. 26, No. 2, pp. 8-11, 2003.

[17] Hoveida, R., Shams, G., and Hooshmand, A., "Knowledge management practices in higher education institutes: A different approach", Digital Information Management, 2008. ICDIM, IEEE, pp. 695-702, 2008.

[18] De Pablos Pons, J., "Higher Education and the Knowledge Society. Information and Digital Competencies", International Journal of Educational Technology in Higher Education, Vol. 7, No. 2, pp. 6-15, 2010.

[19] Drucker, P., in Post-capitalist Society. Routledge, 2012.

[20] García-Peñalvo, F.J., Hernández-García, Á., Conde, M.Á., Fidalgo-Blanco, Á., SeinEchaluce, M.L., Alier-Forment, M., and Iglesias-Pradas, S., "Enhancing education for the knowledge society era with learning ecosystems”, In Open Source Solutions for 
Knowledge Management and Technological Ecosystems, IGI Global, 2017, pp. 1-24.

[21] Machado, C., and Davim, J., "Knowledge management fostering innovation: Balancing practices and enabling contexts", Management and Engineering Innovation (Eds Machado C and Davim JP), John Wiley \& Sons, Inc., Hoboken, NJ USA.

[22] Kafi, N., Shaikh, Z.A., and Shaikh, M. S., "Human Computations in Citizen Crowds: A Knowledge Management Solution Framework", Mehran University Research Journal of Engineering and Technology, Vol. 37, No. 3, pp. 513-528, 2018.

[23] Suciu, M.C., Piciorus, L., and Imbrisca, C.I., "Intellectual capital, trust, cultural traits and reputation in the Romanian education system", Electronic Journal of Knowledge Management, Vol. 10, No. 3, pp. 223, 2012.

[24] Martin, J.S., and Marion, R., "Higher education leadership roles in knowledge processing", The Learning Organization, Vol. 12, No. 2, pp. 140-151, 2005.

[25] Pinto, M., "Knowledge management in higher education institutions: a framework to improve collaboration", Information System and Technologies (CISTI), 2014.

[26] Alavi, M., and Leidner, D.E.,"Knowledge management and knowledge management systems: Conceptual foundations and research issues", MIS Quarterly, pp. 107136, 2001.

[27] Zaki, A.R., and Zubairi, S.A., "The Role of Knowledge Management in Higher Education - A Qualitative Model", Interdisciplinary Journal of Contemporary Research in Business, Vol. 4, pp. 1104-1118, 2012.

[28] Judrups, J., "Analysis of knowledge management and e-learning integration models" Procedia Computer Science, Vol. 43, pp. 154-162, 2015.

[29] Meghji, A.F., and Mahoto, N.A., "Using Big Data to Improve the Educational Infrastructure and Learning Paradigm", Effective Big Data Management and
Opportunities for Implementation, IGI Global, pp. 158-181, 2016.

[30] Denford, J.S., and Chan, Y.E., "Knowledge strategy typologies: defining dimensions and relationships", Knowledge Management Research \& Practice, Vol. 9, No. 2, pp. 102119, 2011.

[31] Han, J., and Miller, H.J., Geographic data mining and knowledge discovery. CRC Press, 2009.

[32] McAfee, A., Brynjolfsson, E., Davenport, T.H., Patil, D.J., and Barton, D., "Big data: the management revolution", Harvard Business Review, Vol. 90, No. 10, pp. 60-68, 2012.

[33] Fayyad, U.M., Piatetsky-Shapiro, G., Smyth, P., and Uthurusamy, R., "Advances in Knowledge Discovery and Data Mining", 1996.

[34] Dunham, M.H., Data mining: Introductory and advanced topics, Pearson Education India, 2006.

[35] Darr, E.D., Argote, L., and Epple, D., "The acquisition, transfer, and depreciation of knowledge in service organizations: Productivity in franchises", Management Science, Vol. 41, No. 11, pp. 1750-1762, 1995.

[36] Bond, M., Marín, V.I., Dolch, C., Bedenlier, S., and Zawacki-Richter, O., "Digital transformation in German higher education: student and teacher perceptions and usage of digital media", International Journal of Educational Technology in Higher Education, Vol. 15, No. 1, 48. 2018.

[37] Han, J., Cheng, H., Xin, D., and Yan, X., "Frequent pattern mining: current status and future directions", Data Mining and Knowledge Discovery, Vol. 15, No. 1, pp. 55-86, 2007.

[38] Agrawal, R., Imieliński, T., and Swami, A., "Mining association rules between sets of items in large databases", Acm Sigmod Record, ACM, Vol. 22, No. 2, pp. 207-216, 1993.

[39] Han, J., Pei, J., Yin, Y., and Mao, R., "Mining frequent patterns without candidate generation: A frequent-pattern tree 
approach", Data Mining and Knowledge Discovery, Vol. 8, No. 1, pp. 53-87, 2004.

[40] Kidwell, J.J., Vander Linde, K., and Johnson, S.L., "Applying corporate knowledge management practices in higher education" Educause Quarterly, Vol. 23, No. 4, pp. 2833, 2000.

[41] Meghji, A.F., Mahoto, N.A., Unar, M.A., and Shaikh, M.A., "Analysis of Student Performance using EDM Methods", 2018 5th International Multi-Topic ICT Conference (IMTIC), IEEE, pp. 1-7, 2018.

[42] Bhusry, M., and Ranjan, J., "Knowledge collaboration in higher educational institutions in india: Charting a knowledge management solution", International Journal of Computer Science, Vol. 8, 2011. 